\title{
A retroductive systems-based methodology for socio-technical transitions
}

\section{research}

Dr George Papachristos*, Dr Emmanuel Adamides ${ }^{1}$

*Corresponding author

Policy Analysis Section

Faculty of Technology, Policy and Management

Delft Technical University

G.Papachristos@tudelft.nl

Policy Analysis Section

Faculty of Technology Policy and Management

Postal address: Postbus 5015, 2600 GA Delft

Phone: +31(0) 152783408

Fax: + $31(0) 152786233$

${ }^{1}$ Division of Management \& Organization Studies

Department of Mechanical Engineering and Aeronautics

University of Patras, Greece

adamides@mech.upatras.gr

\begin{abstract}
Socio-technical system transitions research describes and categorizes transitions and explains and identifies their driving causes. In the literature, transition research frameworks have received some critique on whether they can facilitate the search for transition causes. As a response, and in order to cater for the complexity and contextuality of multi system transitions, this paper proposes a retroductive systems-based methodology. The methodology relies on qualitative case study development and quantitative simulation modelling. Retroduction along with modelling and simulation can contribute to the shift from researching single system/technology transitions to multi system/technology transitions. Thus the paper offers a step towards coping methodologically with sustainability transitions that often concern multi system interactions. We demonstrate the use of the methodology by adopting the Multi-Level Perspective on transitions to explain the emergence of the functional foods as a niche in the food/nutrition socio-technical system.
\end{abstract}

Keywords: socio-technical systems, transitions, research methodology, retroduction, critical realism, system dynamics

\section{Introduction}


Research in sociotechnical transitions and system innovation aims at understanding social and technological change by analysing the causes that enable or inhibit such long term, system level processes. Research in this area faces two challenges (Genus and Coles, 2008): (i) how to create and improve the understanding of historical transitions, and (ii) how to advance and refine the frameworks and tools used for the analysis of contemporary sociotechnical transitions in order to inform and/or propose interventions related to governance and technology policy. These challenges are interrelated and involve generating and systematizing knowledge about how transitions initiate, unfold and finish.

From a systems perspective, transitions can be thought of as changes of state of socio-technical systems. They are transient social phenomena generated by dynamic interactions between system elements and result in long-term structural changes, which permeate the majority of the elements of the system. Although socio-technical systems and system innovation research focus on understanding systems, in reality theoretical frameworks like the Multi-Level Perspective (Geels and Schot, 2007; Geels, 2004) make little use of systems approaches, methods and tools in addition to case studies (Coenen and Diaz Lopez, 2010). In transition research methodologies, the notion of system has been employed only to account for interconnectivity and other static, spatial, conceptual properties of socio-technical systems while system-theoretic and dynamic, quantitative, behavioural approaches have received little attention (Holz, 2011; Safarzynska et al., 2012).

The Multi-Level Perspective (MLP), in particular, has been criticised as offering a heuristic device with which transition events can be organised (Genus and Coles, 2008). It has also been argued that it is limited to single system transitions while in reality, the majority of transitions involve interactions between more than one systems (Papachristos et al., 2013). The existence of single system transition typologies (Geels and Schot, 2007) and the relative lack of multi-system transitions research (Raven and Verbong, 2007; Raven 2007a; Geels, 2007b) can be partly attributed to the limited use of suitable systems-based research methodologies to handle the increased complexity of interactions and their generative mechanisms. Nevertheless, inter-systems interactions are expected to be important in transitions to sustainability (Mancarella, 2014). For example, biofuels for transport link the agrifood, energy and transport systems, and electric or plug in hybrid vehicles link transport and electricity systems.

It follows that a shift from single system/technology to multi system/technology transition frameworks is necessary in order to remain relevant for the future (Geels, 2010; Laurisden and Jorgensen, 2010; Konrad and Truffer, 2008). In researching transitions, there is no other way of inferring their causes except by constructing a plausible narrative about them and assessing its validity 
on the basis of the outcomes it produces. We argue that this requires: (i) the application of a retroductive inference mode under a critical realist philosophical perspective and (ii) modelling and simulation for handling the increased complexity of multi system transitions (Davis et al., 2007; Harrison et al., 2007; Papachristos, 2014). This paper proposes a research methodology for sociotechnical systems transition that retains case studies but also integrates retroduction with simulation modelling putting an emphasis on multi-system transition cases. The combination of models and case studies will yield clearer insights with greater confidence (Buthe, 2002; Kopainsky and Luna-Reyes, 2008; Eisenhardt and Graebner, 2007).

Retroduction has been previously applied in several research areas, for example in technology innovation policy (Gao, 2015). Retroduction is associated with the critical realist philosophical perspective (Peirce, 1958; Bhaskar, 2008) and differs from induction and deduction in that it is a process of forming explanatory hypotheses about the generative mechanisms of an observable phenomenon and then testing them in order to determine their validity (Wuisman, 2005). Retroduction 'is the only logical operation which introduces any new idea and leads to new knowledge' (Peirce, 1991, quoted in Fischer, 2001). In research, it overcomes the limits of induction which are associated with the long transition periods which are difficult to observe directly, as well as those of deduction which relies on a limited number of variables isolated from the complex, dynamic, systemic contexts of socio-technical systems through a series of debatable assumptions.

The methodology presented in the paper, operationalizes retroductive hypothesis testing through system dynamics modelling and simulation. The methodology is applied to a novel multi-system transition case concerning the functional foods niche, which emerged through interactions of event producing mechanisms in the converging socio-technical systems of food and pharmaceuticals (Curran et al., 2010). The question posed for the case was: "which were the operative (underlying) mechanisms in the pharmaceutical and food systems whose interaction resulted in the emergence of the functional food niche in the food socio-technical system?'. This question was answered by forming a qualitative hypothesis about the mechanisms operating in the two systems and testing possible variations through modelling and simulation. It allowed us to see whether specific instantiations of the explanatory mechanisms for the phenomenon form internally consistent hypotheses and are sufficient for generating the observed emergence of functional foods. It also allowed the investigation of the effect of timing and intensity of interactions on the emergence of the functional foods niche, something not possible through a case study. 
System dynamics simulation modelling and simulation of mechanisms was chosen to reproduce the observed phenomenon because: (i) it is suited to modelling cases developed in a narrative style (Kopainsky and Luna-Reyes, 2008), (ii) as a systems methodology is conducive to retroduction (Mingers, 2000; 2004); (iii) it can be used to overcome the limitations of human cognition in assessing feedback, delays and accumulation (Sterman, 1989a;1989b; Diehl and Sterman, 1995; Cronin et al., 2009), and (iv) it can be used for the development of middle range theory (Kopainsky and LunaReyes, 2008; Schwaninger and Grosser, 2008) which is the expressed aim of the MLP (Geels, 2007a). Finally, from its inception, system dynamics has dealt with large scale, long-term issues (Forrester, 1961; 1969; Meadows et al., 1972) precisely the kind of processes that transitions are.

The contribution of the paper is fourfold. First, a retroductive methodology to transition research that can be applied both in MLP related and Innovation Systems research is proposed. It is applied in the functional foods case and allows an in depth exploration and validation of the identified causal mechanisms thus increasing the confidence in the proposed explanation of functional foods emergence. Second, a novel multi system interaction case is presented which adds to the existing literature on transitions. Third, to the best of the authors knowledge, it is the first multi-system modelling effort in transition research as existing models in the literature concern single regime transitions (Kohler et al., 2009; Bergman et al., 2008; Safarzynska and van den Bergh, 2010). Finally, by reproducing the functional food emergence the paper substantiates the proposed new MLP transition pathway proposed in Papachristos et al., (2013).

The rest of the paper is structured as follows: Section 2 presents an overview of systems approaches to innovation and socio-technical transitions, while Section 3 discusses related research design issues. Section 4 discusses retroductive inference and outlines a methodology that integrates modelling and simulation. Section 5 presents the functional foods case and Section 6 develops the hypothesis of how interacting mechanisms result in the new system emergence. This is followed by the development of the system dynamics model and the presentation of the results of its simulation. Finally, section 7 concludes with discussion of results and suggestions for further research and development.

\section{System Approaches to Innovation and Technical Change}

Extensive literature exists on conceptualisations of system innovation and technical change (Freeman, 1987; Lundvall, 1992; Nelson, 1993). There are several strands of innovation systems research: sectoral, regional and national (Mowery, 1998; Carlsson et al., 2002; Lundvall, 2010). They differ from traditional black-box economic approaches that emphasise spending/input. The common ground in their systems perspective is that innovation, technological and economic performance are 
contingent on the interactions and learning between system elements (institutions and/or organisations) (Edquist, 1997). In the same line, Technological Innovation Systems (TIS) (Carlsson and Stankienwicz, 1991), and Functions of Innovation Systems (Bergek et al., 2008; Hekkert et al., 2007), emphasize the dynamic analysis of system functions and their interactions: knowledge development and diffusion, influence on the direction of research, entrepreneurial experimentation, market formation, legitimation, resource mobilization and development of positive externalities.

Socio-technical systems approaches differ from the above in that they broaden the unit of analysis from the firm level to the organisational field (DiMagio and Powell, 1983), they introduce societal processes (e.g. consumption and use), and have an overall sociological, rather than economic, orientation (Coenen and Diaz Lopez, 2010). For example, the MLP is concerned with the interconnections and the dynamics of social groups that influence technological change and system inertia. In general, a socio-technical system comprises of the elements that are necessary for fulfilling a societal need such as nutrition and includes the corresponding industrial organisation. The system is the "product" of the activities of actors who are embedded in interdependent social groups, each with its own set of operating rules and behavioural norms.

In the MLP discourse, the socio-technical regime is the central concept for analysing actor activities and how they reproduce or change the system. It is where incremental technological development and consumer preferences co-evolve defining the trajectory of the regime. The regime can be considered as a specific state in the trajectory of a socio-technical system, which is contingent to intangible and underlying institutional structures e.g. engineers' heuristics, institutions and social expectations (Geels, 2011). There are two additional levels in the MLP-based analysis (Geels, 2004): the landscape, at the macro level, which provides long-term gradients for the regime trajectories, and the niche, at the micro level, where radical innovations incubate and proliferate.

A transition takes place when the regime is destabilised through pressures and interactions that develop between the three levels until a new system state is reached (Geels, 2010). Regime stability can be perturbed by (Geels and Schot, 2007): (i) innovations that develop in niches through learning processes, price/performance improvements and support from powerful groups, (ii) pressures accumulating from events or trends at the landscape level acting on the regime (economic, cultural, demographic etc), (iii) internal tensions that can destabilise the regime and create windows of opportunity for innovations in niches, (iv) influences from external regimes or different systems i.e. multi regime or system interactions (Papachristos et al., 2013). 
Clearly, sociotechnical change cannot be attributed to a single driving interaction or pressure but to processes at multiple levels, enmeshed in feedback loops, which reinforce or counter each other. The study of sociotechnical change amounts to understanding how intra- and inter-system interactions unfold over time, and how their nature, timing and intensity can enable, or constrain, a transition. Different interactions can result in different transition pathways (Geels and Schot, 2007). However, while most of the exemplary transition cases in the literature, on which the MLP is based, document some outside influence to the sociotechnical regime and/or niches (Papachristos et al., 2013), transition frameworks have not been extended to fully accommodate multi-system interactions and there are no documented suggestions of appropriate research methodologies either. This paper aims at filling this gap.

\section{Research Design Issues in Systems Innovation and Transition Research}

The fundamental research requirement for socio-technical systems remains the study of system elements interactions, their mechanisms, and the changes that they produce. These may include lockin mechanisms, scale economies, infrastructures, firm competencies, institutional commitments, shared beliefs and discourses, power relations, consumer preferences and incumbents' vested interests (Garud and Karnoe, 2001; Unruh, 2000). Such mechanisms need to be understood as temporal functions because they result in path dependence, system inertia and trajectories of specific orientation. The way the considerable number of historical transition cases can be effectively used for policy making and for steering contemporary socio-technical systems towards desired states is through identifying such generative mechanisms and situating them in these systems.

Nevertheless, this is not the case so far. In addition to qualitative research, empirical studies have relied extensively on descriptive, or comparative statistics and correlations, neglecting more dynamic analysis methods (Carlsson and Jacobsson, 2002; Hekkert et al., 2007). On the other hand, simulation modelling has mainly been employed as a prospective experimental apparatus to assess the effects of different policies on innovation-related performance metrics, or reproduce specific transitions (Bergman et al., 2008; Kohler et al., 2009; Schilperood et al., 2008; Safarzynska and van den Bergh, 2010; Papachristos, 2011; Samara et al., 2012). The emphasis was mostly towards policy making on already existing innovation system configurations, not on understanding generative mechanisms of a specific transition case or a set of cases.

But, since the MLP aims at process theorizing (Geels, 2011), it should not be limited to descriptions but penetrate the logic behind observed temporal progressions, whether simple or complex (Van den Ven, 1992). Doing so would constitute part of the response to the critique the MLP has received 
regarding its epistemological value (Shove and Walker, 2007; Hommels et al., 2007), expressed as (Genus and Coles, 2008, p1442): "potential contribution of the MLP/transitions framework could be limited to offering a heuristic device that can be used to organise sets of data". This critique is consistent with the view concerning organisational research according to which variables or constructs do not constitute a theoretical contribution without an underlying causal logic (DiMaggio, 1995; Sutton and Staw, 1995; Whetten, 1989).

So far, the response to these criticisms has been in two directions (Geels, 2010). First, in the argument that the use of open heuristic frameworks may be more suitable for investigating transition dynamics in comparison with the use of precise formal/deductivist models. It is argued that the MLP, being a heuristic framework, leaves room for scholars to perceive and conceptualize different dynamic mechanisms operating in particular transitions by developing auxiliary theories or hypotheses that are more suitable for a middle range theory (Geels, 2007a). Second, by insisting that the MLP follows a process theory explanatory style (Geels, 2011), and that it does not attempt to explain transitions as causally driven by independent variables, but in terms of patterns of events that take place at the empirical (observed) level, leaving the interpretation to the observer. The causes of the events can be found in intangible mechanisms that operate in a socio-technical system.

The difference between system and regime is important in understanding this logic, as systems under the MLP refer (Geels, 2011, p 31): "to tangible and measurable elements ... whereas regimes refer to intangible and underlying deep structures". This statement implies that there are measurements and observations of a particular socio-technical system which can be associated with a particular system configuration/regime. However, the structure that produces these measurements and observations is not directly accessible because it is intangible and there is no rational way of deducing the regime from the observations.

In the study of socio-technical system transitions this link between causes and effects was considered at a single uniform ontological level of observable events. The MLP transition typology (Geels and Schot, 2007) is based on a correlative logic in which "if Condition then Transition Pattern" statements are made based on observing transition pattern and their effects. For example, (Geels and Schot, 2007, p 308):“If landscape change is divergent, large and sudden ('avalanche change'), then increasing regime problems may cause regime actors to lose faith. This leads to de-alignment and erosion of the regime. If niche-innovations are not sufficiently developed, then there is no clear substitute". Given the transitive nature, associating conditions with new system states does not necessarily reflect or 
lead to the desired identification of causal relations between mechanisms and patterns (Bhaskar, 2008).

For example, following the MLP criteria of nature, timing and intensity of interactions, it is conceivable that reinforcing interactions may be taking place while others are countering them, with the result being that a stagnant situation, rather than a dynamic change, is observed. The converse situation is also possible. Hence, observing a transition pattern and stipulating by induction that some reinforcing and countering interactions are taking place can lead to fallacious inferences. This applies also to other innovation systems approaches that aim to identify blocking mechanisms or countering interactions and to propose policies for their removal (Bergek et al., 2008). Accounting for the effects of timing and intensity of interactions necessitates an analytical shift from interpreting empirical correlations to testing generative mechanisms for which induction is not the appropriate inference mode.

The majority of the MLP related research utilises primarily narrative and event data in order to build an understanding of transitions. The primary benefit of narratives is that they can convey and expose evidence and their context in a way that quantitative approaches cannot (Pettigrew, 1992; Yin, 2003). This is just one out of a range of available strategies for developing process theory (Langley, 1999). Each one entails certain tradeoffs between accuracy, generality and simplicity (Weick, 1979) and has different strengths and weaknesses (Langley, 1999). Narrative and simulation strategies lie at the two ends of a continuum that opposes empirical accuracy and theoretical parsimony and their combined use is in a position to offer a better trade off between accuracy, simplicity and generality than narrative alone. It follows that simulation strategies, will be more convincing if used in combination with approaches that allow contextualization of abstract data, adding nuances of interpretation and confirming the mechanics of simulation models with direct evidence. Thus, our proposed methodology adheres to a narrative strategy because almost all process research involves recourse to a narrative strategy at some point (Langley, 1999), but also integrates modelling and simulation. There are additional reasons for doing so.

Transitions are complex dynamic phenomena. Hence, studying them through mental experiments alone is haphazard, as there are inescapable human cognitive limitations. These have been empirically identified as the "misperception of feedback" (Sterman, 1989a; 1989b) and "stock and flow failure" (Cronin et al., 2009; Diehl and Sterman, 1995; Sterman and Sweeney, 2007). People systematically misperceive feedback, cannot estimate the effects of interconnected delays and have a poor understanding of accumulation or depletion processes, which are also present in transitions (Raven, 
2007b; Geels, 2005). This necessitates the use of simulation for researching the underlying mechanisms responsible for socio-technical transitions.

\section{Simulation Modelling in Transition Research with Critical Realism as Underlying Philosophy}

Simulation modelling has been frequently used for foresight or demonstrating the value of specific modelling techniques for transitions research. Holtz (2011) and Safarzynska et al. (2012) provide reviews on the use of different modelling formalisms in transition research. in these, a specific system is modelled, the model is validated and future projections are made by simulating what-if scenarios frequently associated with different events or policies. This use of simulation assumes a positivistic philosophical stance, i.e. that the world is and continues to be as the modeller thinks.

Nevertheless, studies of transition frameworks are not based on a positivistic ontology. Their principal objective is not to predict or provide prescriptions, but to understand phenomena, and the underpinning ontology of the MLP is a crossover between interpretivism and evolutionary theory (Geels, 2010). This explains its methodological bias towards qualitative research and case studies and is reflected in associated meta-analysis studies and in the development of typologies of transitions (Geels and Schot, 2007). This leaves a limited space for a conventional use of simulation modelling since an interpretivistic ontology adheres to a very fluid ontology overemphasising the role of the researcher in the research process (Adamides et al., 2012). Consequently, a methodological shift in the use of modelling and simulation necessitates a corresponding shift in the underpinning philosophy of science. Situated between positivism and interpretivism is critical realism (Bhaskar, 2008; Archer et al., 1998), which admits the existence of a more complex, multi-level reality (ontology), and challenges the ontological assumptions and certainties of the positivist paradigm through qualitative and multi-faceted, pluralistic research methodologies employing a retroductive mode of inference.

\subsection{Critical Realism}

Critical realism posits that a more complex, multi-level reality (ontology) exists. It aims at challenging the ontological assumptions and certainties of the positivist paradigm through qualitative and pluralistic research methodologies employing a retroductive mode of inference. Critical realism accepts the relative independence of an ontological domain from the domain of observed events. It accepts that an independent world of structured reality exists (the domain of the real) containing generative mechanisms that are independent from the observer. They generate events situated at the domain of the actual, which may also exist independent of the observer. What the observer/researcher experiences from the domain of the actual constitutes the empirical domain (Sayer, 2004). A critical 
realist perspective has been applied in $\mathrm{CO}_{2}$ emission scenarios and biofuels diffusion (Upham et al., 2014; Boucher, 2012).

For critical realists, social constructions do exist and some of them may be (re)defined and/or influenced/altered by observers. However, this presupposes that certain practices or constructions exist independently from those an observer can influence (Sayer, 2004). These institutionalised and socially qualified practices that cannot be influenced effectively constitute the domain of the real and they are referred to as socially real (Fleetwood, 2005). This essentially implies a view of organisations and other social groups involved in transitions, as structures of positions-practices and relations between them, developing in time and space (Reed, 2009). Hence, in a critical realist perspective, socio-technical systems can be conceptualised ontologically as consisting of interlinked objects, which are part of structures (mechanisms) having innate causal powers (or tendencies) and liabilities activated under specific conditions. These then generate change in sociotechnical systems.

This logic of generative causality implies that ensembles of causal mechanisms possess the power to influence reality and/or the tendency to exhibit particular behaviours and generate events that are experienced by humans at the empirical level. Generative mechanisms are thus real and distinct from the events and patterns they generate and, in turn, events are real and distinct from human experiences by which they are cognised (Bhaskar, 2008). The observed events are the outcome of all the mechanisms operating simultaneously, which however may not necessarily have an empirically manifest outcome when operating separately (Archer et al., 1998). It follows that knowledge creation about a phenomenon is produced by uncovering these mechanisms and their causal powers. This can be done by producing a generative hypothesis where an ensemble of mechanisms operate in one way or another, and leaving room for different outcomes or transition pathways than those the system actually produces. Mechanism are then subjected to empirical scrutiny and their explanatory power is evaluated against competing explanations (Wuisman, 2005). This is the core idea underlying retroduction as a method for uncovering generative mechanisms and explaining phenomena.

\subsection{Retroductive Inference}

Retroduction begins with an observed phenomenon $\mathrm{X}$ for which no satisfactory explanation can be formed based on existing knowledge i.e. there is a theoretical gap (Figure 1). One or several competing hypotheses $\mathrm{H}$ involving mechanisms that generate $\mathrm{X}$ are formed by abduction based on a theoretical framework. The validity of each hypothesis is assessed by deducing its logical consequences or observing the behaviour of a form of representation of the underlying eventproducing system/mechanism, e.g. of a simulation model. What is the case in the real world is 
determined by induction and a judgement is made on whether the previously deduced consequences have happened, which would thus provide support for $\mathrm{H}$ as an explanation for $\mathrm{X}$. If this is not the case then a new cycle of abduction, deduction and induction takes place.

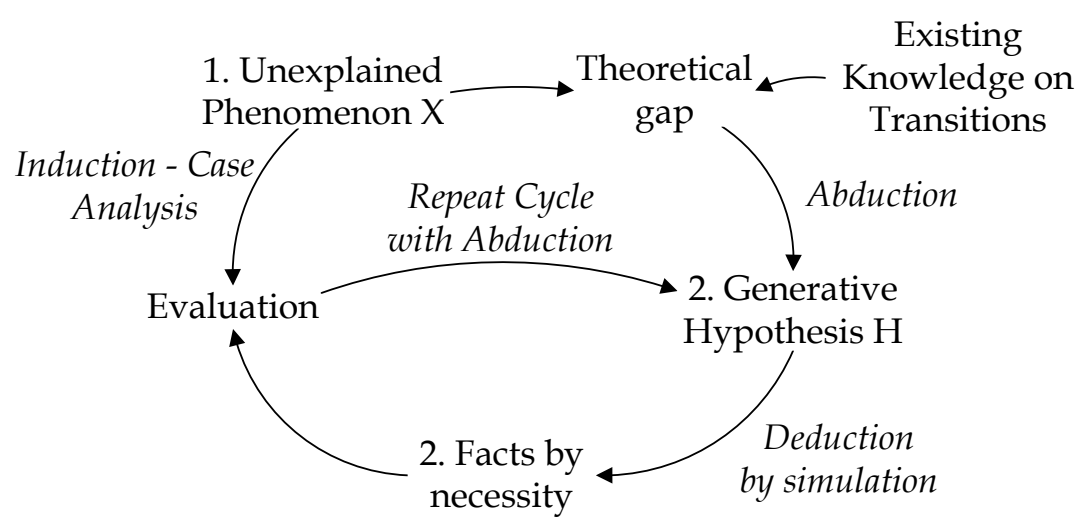

Figure 1. The use of the retroductive inference mode

This process transferred to the context of socio-technical transition research amounts to identifying the mechanisms and accounting for their non linear interactions (Manicas, 2006) in order to explain an observed, novel socio-technical system state that cannot be explained by linearly extrapolating trends and behaviours (Genus and Coles, 2008). This development in research methodology may bring about concomitant development in transition typology of Geels and Schot (2007).

\subsection{A Retroductive Systems-based Methodology for Transition Research}

It has been suggested that if transition research is to remain relevant there is a need for methodological advances, particularly regarding multi-system interactions and transitions to sustainability (Geels, 2011; Laurisden and Jorgensen, 2010). Based on the above discussion, we argue that the use of system dynamics in a retroductive mode in complement with qualitative research approaches can provide a way forward by which it is possible to deduce the effects of non-linear generative mechanisms operating simultaneously and when there are feedback loops and delays among then (Sterman, 2000). System dynamics aims to create endogenous explanations of system behaviour and the problems that they face (Richardson, 2011). Drawing on Danermark et al. (2002) the methodology proposed in this paper comprises three steps related to Figure 1:

\section{Identification and characterisation of the transition phenomenon-development of case.}

First, the main characteristics and processes of the transition which is to be analysed have to be identified and documented. This step answers the "what" question (Whetten, 1989). The important elements of the socio-technical system and their linkages need to be identified and described in some detail. This necessitates the development of a narrative about what is observed as part of a fully 
developed case study. It requires both qualitative (historical archives, interviews with experts, etc.), and quantitative research (e.g. time series) about the transition. The main variables that characterise or define regime shifts need to be identified and operationalized as an input for steps 2 and 3 .

\section{Conjencturing generative mechanisms}

This step involves creating generative hypotheses about the mechanisms operating in a transition. It provides potential, plausible answers to the "how" question. This step may be more effective if different researchers introduce different perspectives which are debated in a structured manner using a methodology such as the Soft Systems Methodology (SSM) (Checkland and Scholes, 1999). SSM provides a methodological map for reaching an accommodated view in an issue for which different perspectives hold. The result of this phase will be an account of the socio-technical system under consideration in a more fine-grained analysis including the generative mechanisms in the system, and the conditions that enable the causal powers and liabilities of their structure. This may be crystallized in a causal loop diagram (Sterman, 2000) and constitutes the input to step 3.

\section{Modelling of system structure and simulation under different hypotheses}

In this step, a system dynamics model of the socio-technical system and its mechanisms is constructed. Different hypotheses are simulated and the results are assessed corroborating against real world events. This reveals which hypothesis is sufficient to generate the observed transition events and thus provides an answer to the question of "why" a transition actually happened.

In the following sections, an example of applying these steps is given. The phenomenon under study is the emergence of functional foods as a niche of the food/nutrition socio-technical system. Assuming that functional foods are related to both the food/nutrition and the pharmaceuticals-based treatment socio-technical system, the main research question may be phrased as 'which operative mechanisms in the pharmaceutical and food socio-technical systems are responsible for the emergence of the functional foods system?'. To answer, after developing a case narrative, we conjecture on generative mechanisms whose modelling and simulating is used to reproduce the phenomenon. Then, the results of the simulations are discussed in the context of whether (or not) they reproduce the phenomenon.

\section{The Case of Functional Foods Emergence}

Functional foods, or nutraceuticals, are an innovative category of food that can be considered as a niche of the current food socio-technical system. They do not constitute just a product, or incremental innovation because their emergence has been associated with changes in relations between several social groups (Kallinikos et al., 2013): food producers, consumers, patients, physicians, medical 
associations, governmental agencies, as well as between the artefacts per se and consumers. Functional foods are associated with know-how of biotechnology that originated from the pharmaceuticals industry, and are directly linked to specific diseases. At the same time, functional foods are still food, which historically has been associated with everyday life practices and "lifestyle".

Functional foods are similar to conventional food but offer additional health benefits such as illness risk reduction, prevention and most importantly, treatment of diseases (Best, 1996; Mark-Herbert, 2004). Functional foods can be viewed as products containing substances with health-improving properties (e.g. plant sterol/stanol esters that reduce the risk of coronary heart disease), promoted through health improvement claims made by their producers and their supporters. These claims are based on technical, objective data instantiated in the evidence-based logic and the support of clinical studies certified by medical associations (e.g. the heart diseases medical associations) (Miettinen, et al., 1995). The social dimension and systemic nature of the innovation of functional foods is amplified by their definitional ambiguity and by the absence of a consistent associated legal framework (Doyon and Labrecque, 2008). Their public image as health promoting products is associated with the notion and identity of the consumer-patient, and with artefacts such as medical statistics, results of clinical trials, specialised scientific workshops, and packaging information constituting boundary objects between producers and social groups (Eden, 2011).

Following the MLP logic, subsequent sections identify developments and trends in the emergence of functional foods at the landscape and regime levels. Seven propositions of mechanisms are outlined which are thought to be operating and driving the trajectory of the systems interactions. They are then consolidated into a single causal loop diagram as the transition's generative hypothesis to be tested through simulation modelling. The outcomes of simulations are then presented and discussed in Section 6.

\subsection{Landscape Level: Overarching Trends}

Two large-scale shifts have taken place in the last decades: the shift in individual life styles in the developed world, and the global demographic shift. Both are directly related to maintaining individual health through healthy nutrition preferences, and increased health care costs for a growing ageing population. The link of nutrition to health has been firmly established (Potter and Steinmetz, 1996; Lorgeril et al., 1998). Awareness of this fact has changed individual lifestyles towards enjoying food without compromising health, or forgoing the ingredients that are essential to maintain human physiological functions within normal levels. The awareness of the link between nutrition and individual health has also increased because cases where food products for human consumption had 
adverse effects received widespread media attention in the late 1990s and early 2000s (BSE, dioxins etc). This shook consumer trust in food quality and the ways it is produced. As a result, consumers sought nutritional guidelines and information about what they consume, and became more willing to change their nutritional habits. Hence, we propose the mechanism:

\section{M1: food crisis and change in life style $\rightarrow$ less trust and seeking more information about food}

The second shift is demographic and has three components: (i) an increase in average life expectancy, (ii) population growth, and (iii) a shift in age stratification. In most developed countries, senior citizens are a significant percentage of the population. This influences the health care system, the requirements for physicians and other skilled personnel, the demand for hospital beds and equipment, and the need for long-term institutional care facilities and home care services for the elderly (Denton et al., 2002). The increase of average life span places the health care system under pressure because the additional years of life are not necessarily spent in good health. For example, the incidence of alzheimer, osteoporosis, and chronic cardiovascular diseases has increased. A factor that has been shown to exacerbate this is the increasing level of obesity in developed countries (Mermel, 2004; Muller et al., 2008).

Increases in health care expenditure across developed countries are also attributed to technology, which can amount to one third of per capita cost (OECD, 2006; Okunade and Murthy, 2002; Newhouse, 1992). Investing in medical technology R\&D in order to improve healthcare services is a driver of cost per capita, and has an ethical aspect to it, as improving health care services is considered to be imperative. Health expenditure is also driven by individual income growth, which is strongly related to GDP per capita growth in developed societies. People who can afford to pay for a better and more expensive treatment will generally do so (Hearle et al., 2003). Another driver of healthcare expenditure is the incentives embedded in reimbursement systems for patients and providers (Jacobzone, 2000). For example, spending on pharmaceuticals accounts for $17 \%$ of total health expenditure in Europe and has grown faster than other major components of the health care system since the late 1990s (DiMasi, 2003).

Controlling these cost drivers is difficult because demographic changes take a long time to manifest. The alternative for governments faced with the pressing need of controlling health care costs is to motivate individuals to be proactive about their health (Coveney, 2003). This includes fitness and nutritional habits that improve individual health and alleviate the need for treatment with expensive medicines. There is some overlap between providing for population nutritional needs and maintaining 
or improving human physiological functions, like digestion for example. Functional foods lie in this area of overlap as they are specifically aimed at addressing nutritional and physiological needs simultaneously (Niva, 2007). This provided a business opportunity that led to their emergence and proliferation, which has gained pace with advances in life sciences, particularly biotechnology and molecular biology. On the basis of these observations, we propose the following mechanisms:

\begin{tabular}{llll}
\hline M2: & $\begin{array}{l}\text { increase in health care } \\
\text { costs }\end{array}$ & $\rightarrow$ & $\begin{array}{l}\text { need for more } \\
\text { preventive health care }\end{array}$ \\
\hline M3: & $\begin{array}{l}\text { need for preventive } \\
\text { health care }\end{array}$ & $\rightarrow$ & $\begin{array}{l}\text { need for preventive, } \\
\text { healthy food }\end{array}$ \\
\hline M4: & $\begin{array}{l}\text { need for preventive, } \\
\text { healthy food }\end{array}$ & $\rightarrow$ & business opportunity \\
\hline M5: & business opportunity & $\rightarrow$ & $\begin{array}{l}\text { more intensive scientific } \\
\text { research }\end{array}$ \\
\hline M6: & $\begin{array}{l}\text { business opportunity } \\
\text { and scientific research }\end{array}$ & $\rightarrow$ & $\begin{array}{l}\text { drive for diffusion of } \\
\text { functional foods }\end{array}$ \\
\hline
\end{tabular}

\subsection{Regime Level: Pressures on the Two Systems}

This section provides an overview of the two systems of the case, and the developments that took place at the regime level. The pharmaceutical industry is highly regulated in order to secure product safety, intellectual property and pricing (Brannback et al., 2002; Allarakhia and Walsh, 2011). Industry competition is driven by R\&D speed and spending, drug discovery, and patented marketing. A significant difference with the food industry is the level of R\&D investments. It is approximately $1 \%$ of net product sales in the food industry, while for the pharmaceuticals it 15\% (EFPIA, 2014). Moreover, pharmaceuticals are expensive, and, in most developed countries, part of their market price is covered by public health care system funds. In contrast, food is consumed daily and the consumer pays the full price. Furthermore, consumers in the food system are supplied directly by the food industry, whereas in the pharmaceutical system this is usually done through physicians and pharmacies.

\section{The Pharmaceuticals-based Health-maintenance Socio-technical System}

Over the last decades, several important industry changes occurred in the pharmaceuticals system in OECD countries partly driven from regulatory changes and partly by the adaptation of industry incumbents to new market conditions (Jacobzone, 2000; Allarakhia and Walsh, 2011). Technologies and user/patient attitudes are also changing (Tierney et al, 2013). Drug development and clinical trials became lengthier, costs in the industry increased, new drug patents had a much shorter time of market exclusivity in the 1990s than in the 1970s, and competition from generic drugs became fiercer as their market share grew from 22\% in 1985 to $67 \%$ in 2000 (DiMasi and Paquette, 2004; Grabowksi and 
Kyle, 2007). The average cost of the clinical phases increased fivefold between 1987 and 2000 as the total amount of time required for a successful drug to reach the market increased from 6.7 years in the 1970s, to 9.1 years in the mid-1990s (DiMasi, 2001) and more stringent regulations resulted in declining productivity (Jensen, 1987). These factors lead firms to search for alternatives to R\&D based capability development as the means for creating and sustaining competitive advantage. A number of firm mergers materialised to secure economies of scale and to gain a larger share of the market, but also for building a wider R\&D portfolio and enter biotechnological research (Cockburn and Henderson, 2001). From these, we propose the following mechanism:

\section{M7: need to compensate for $R \& D$ cost increase $\rightarrow$ exploitation of more business opportunities}

\section{The Nutrition Socio-technical System}

In the late 1990s high publicity cases of substandard production processes raised consumer awareness about food quality and safety issues (Rohr et al., 2005). Consumer confidence in governments and in the food and agriculture industries was shaken, and food quality and safety became a concern (Coppens et al., 2006). Driven by information flows and safety worries, consumers in developed countries became more demanding and more fragmented in their food choices, thereby driving the differentiation of food products. As a result of the increased public awareness on food safety issues, organic production, animal welfare, and the use of genetically modified organisms in food production, received wide attention (Verbeke, 2005).

At the same time, the improvement of standards of living, the shift in social norms towards having a 'balanced diet' and an increasing public interest regarding nutrition and health issues marked a clear and substantial shift in consumer attitudes towards products that can contribute to this. Nowadays the consumer's belief that appropriate nutrition contributes to health is stronger than ever (Silventoinen et al., 2004). It translates to a need for a sufficiently varied food choice to ensure an adequate intake of essential nutrients and keeping calorific intake in balance with basic metabolism and physical activity. This is another socio-biological reason for the emergence of the functional foods.

\subsection{Niche Level: The Emergence Of Functional Foods}

The emergence of functional foods can be broken down in three phases. In the first phase (1980s), there were very low landscape pressures, with no interaction among the two 'parent' industries. Functional foods had not yet gained market share. In the second phase (1990s), sales increased and technology developed further. The strategy of companies also changed and campaigns aiming at 
raising consumer awareness appeared on the media. In a move to strengthen their market foothold, companies indirectly promoted their products by gaining support and/or approval by health and other medical societies and institutions. In the third phase, socio-demographic trends persisted and there was evidence of intensifying collaboration between the two systems. Sales increased as product promotion intensified through organising related conferences, and university research and education becoming ever more involved with incumbent members of the industry. Finally, the third phase was marked by the food crises in the late 1990s (the cases of BSE and dioxins in fish), which shook consumer trust in food choices and triggered consumer search on nutrition alternatives.

Regulating information provision and scientific proof for the risks and benefits of functional foods for consumers is necessary, as the potential risk associated with the product is the most important factor influencing its selection and use (Cardello et al., 2007). It is also important because their benefits cannot be experienced directly (Bagchi, 2008) and this can slow down their adoption (Rogers, 2003). The only way consumers can make an informed choice is by trusting the information concerning the additional benefit of the functional product (Bech-Larsen and Scholderer, 2007). Consumer trust in public health officials and scientists (Titchener and Sapp, 2002), in regulatory institutions (Frewer et al., 2002) and in food producers (Frewer et al., 2003) is an essential factor for the diffusion of functional foods. From this we propose the following mechanism:

\section{M8: food related regulation and information $\quad \rightarrow \quad$ increase in public trust in food}

An important source of information about food quality and safety are the mass media. They can have both positive and negative impact and influence consumers to include in their diets products with health benefits (Rohr, 2005). This can create, or intensify, a business opportunity for the food industry. There are two reinforcing factors driving consumer attitudes towards what they perceive as more safe and healthy choices: (i) the negative publicity of nutrition cases and (ii) the increasing discretionary income of consumers which can be used to purchase safer products. From this we propose the following mechanism:

\section{media information \\ M9: dissemination about functional foods}

On the basis of the above discussion, and having in mind mechanisms M1 to M9, it becomes clear that elements of the two 'parent' systems coalesced in response to aggregate pressures and trends, as well as market failures and demand in order to take advantage of the emerging business opportunity. Hence, the main explanatory hypothesis becomes that the emergence of functional foods was the 
result of the activation of mechanisms that resulted the development of a business opportunity, their production and adoption, and the subsequent regulation of the products and production processes. In the following section, this hypothesis is tested by using a dynamic simulation model that represents the above mechanisms. Variations of the main mechanism objects (variables), producing different versions of the hypothesis, are also tested in the context of the retroductive methodology.

\section{Modelling and Hypothesis Testing}

Drawing on the exposition of the case in the previous section a more concise, detailed hypothesis is put forward in this section for the emergence of functional foods. Following the MLP perspective, niche regime and landscape levels are clearly demarcated (Figure 2). The landscape trends and pressures acting on the two systems, the consumer trends and the way they all interact and result in the emergence of the new system constitute the dynamic hypothesis depicted in the form of causal loop diagram (Figure 2). In the particular context, a causal loop diagram represents the mechanisms and the interactions which produce the events observed or the observed behaviour of specific variables (objects) that characterise the state of the system. The plus sign is used to indicate that a variable ceteris paribus has a reinforcing effect on another and a minus indicates a negative effect.

The model represents five driving forces acting on the two systems (shown in bold in Figure 2) that activate the aforementioned mechanisms. First, new technologies enable novel drug development, regulations impose strict controls on drug approval, which translates into lengthier clinical trials, increased development cost and a need to reduce it (Drug_PLC_Cost_Trend). Second, scientific research through the public discourse and media raises public awareness about the link between diet and health, and research on functional foods increases consumer trust in them (mechanism M8-9). In turn, this removes the reservations of individuals to make dietary changes as awareness of the public on the diet - health link strengthens and the efficacy of functional foods is proven (this has been aggregated into Scientific_Research). Third, Demographic_Trends in OECD countries, drive health care cost and subsequently the need to reduce it (mechanism M2). Health awareness initiatives taken by government promote the link between diet and health, based on research data (mechanism M3), and further intensify this link by the opportunity seen in treating food (mechanism M4, M5, and M6). Fourth, the increase in wealth (GDP/Income growth) in developed countries results in people choosing better and more expensive treatments. Finally, Food Crises reinforces the consumer's search for alternative nutritional options (mechanism M1). These drivers eventually result in the development of functional food system capacity, defined as the Capability_and_Resources_of_the_2_Systems and the niche actors involved in functional food production. 


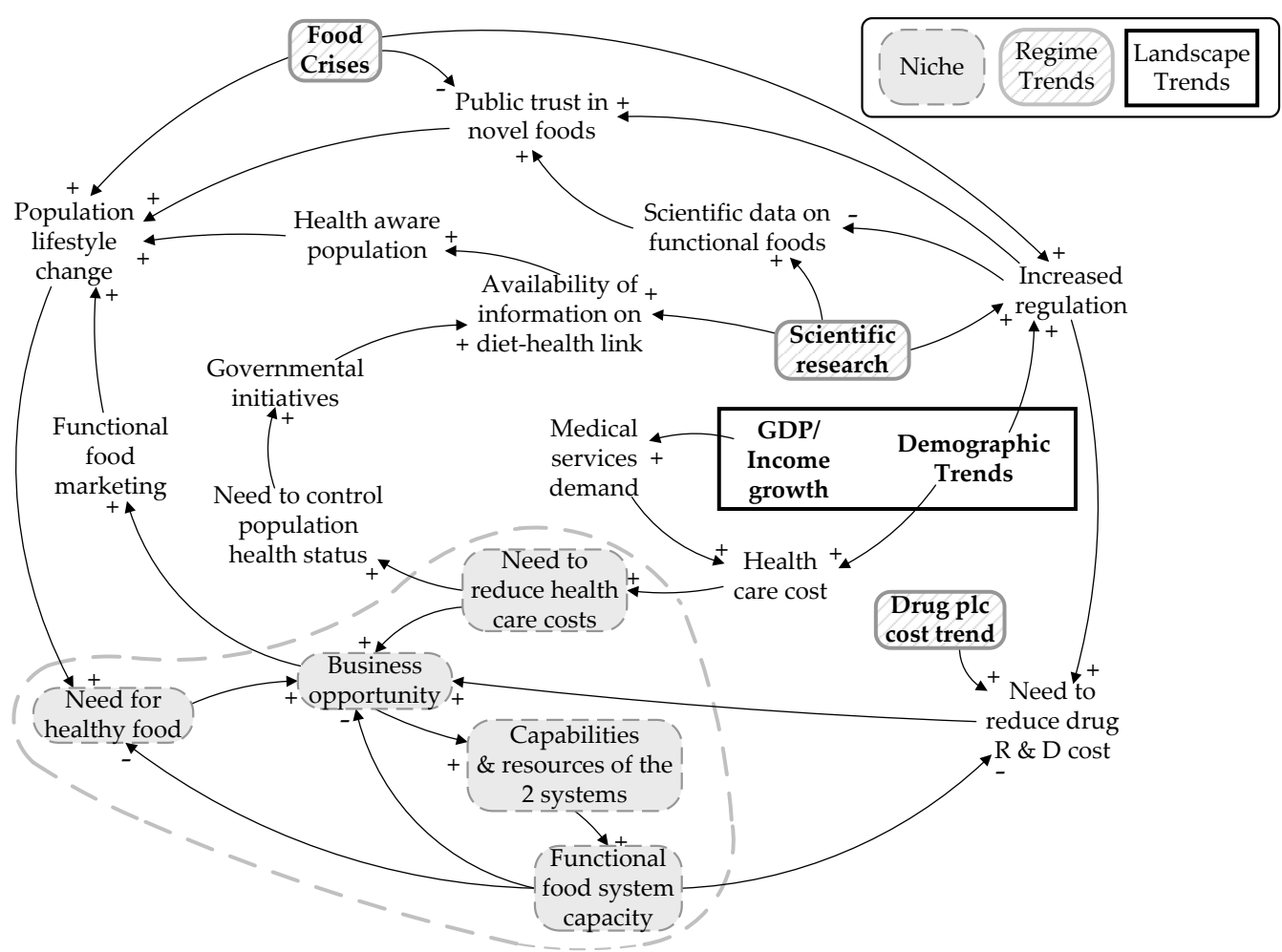

Figure 2 Causal loop diagram of the mechanisms for the emergence of functional foods

The hypothesis on the emergence of functional foods was tested by translating the above causal loop diagram into a system dynamics model making additional assumptions about the boundary of the system, the drivers that influence the two 'parent' systems and their consequences in terms of the shifts observed in the functional food market size. For instance, instead of modelling in detail the drivers of health care expenditure to generate endogenously health care cost trends, Health_ Care_Cost is an exogenous variable taking values using OECD time series data of average public expenditure on health care per capita in US\$ Purchasing Power Parities (OECD, 2006).

Similarly R\&D cost in the pharmaceutical industry was modelled using time series data (DiMasi et al., 1991; Scherer, 2001; Coveney, 2003) without modelling endogenously the effects of regulation, investment lags and firm demographics parameters. The effect of scientific outcomes was also modelled exogenously based on two-time series from 1950 to 2010. One for research on publications regarding the nutrition health link and the other for functional foods, constructed by online search using several key word combinations. Assumptions were made about the adoption of functional foods by consumers (Population_Lifestyle_Change). In the model, population dietary shifts in the model are not restrained by structural or economic issues (Ashton and Seymour, 1990) while it is also assumed that demographic dynamics do not influence food availability and supply. Food_Crises models the effect that cases of substandard food products or production processes had on public awareness. In the model, this is represented as a single continuous event from 1995 to 2005 and takes 
its maximum intensity of 1 during the years 2000 - 2004. It raises public awareness on personal health issues and motivates people to be actively informed about nutrition matters and adopt products such as functional foods.

The main structure of the system dynamics model has four consumer state variables (stocks): $S_{1}, S_{2}$, $\mathrm{S}_{3}$, and $\mathrm{S}_{4}$. Consumers in $\mathrm{S}_{1}$ are not aware about the diet-health link. In $\mathrm{S}_{2}$ they are aware about the role of nutrition on their health and in $S_{3}$ they are willing to make changes in their nutritional habits actively seeking and evaluating choices. $\mathrm{S}_{4}$ represents only those consumers/patients that use functional foods. Consequently, there are three transition flows between population states in the model: in awareness $\left(\mathrm{T}_{\mathrm{A}}\right)$, in willingness $\left(\mathrm{T}_{\mathrm{W}}\right)$ and in diet $\left(\mathrm{T}_{\mathrm{D}}\right)$ towards the use of functional foods. Equations $1-4$ below regulate the flow of consumers/patients towards the adoption of functional foods. A complete list of equations is provided in Appendix A.

$\mathrm{T}_{\mathrm{A}}$ is given below:

$$
\mathrm{T}_{\mathrm{A}}=\left(\mathrm{GI} \times \mathrm{x} \text { CSI }+ \text { FF_marketing }+\mathrm{WoM}_{\mathrm{A}}\right) \times(1+\mathrm{EoC})
$$

where GI is the Government_Initiatives aiming to increase public awareness about health. GIs arise out of the need to contain rising health care costs and inform people about healthy nutrition effects. CSI (Consumer_Science_Influence) is the influence scientific results have on the behaviour of consumers. CSI expresses the influence of science on consumer awareness about nutrition due to dissemination of scientific knowledge in popular science and lifestyle journals. GI and CSI have a multiplicative effect because governmental initiatives aim at raising public awareness about an issue by using already established scientific facts. The assumption with the multiplicative formulation is that their effects are not separable (Sterman, 2000). At the limit without any scientific base, government initiatives would be vacuous. In principle this is similar to the case where population birth rate is zero when food per capita is zero irrespective of changes in other conditions. This clearly cannot be captured with the additive formulation and the multiplicative formulation is required. $F F \_$Marketing is the effect of functional food marketing on people's awareness of functional food. $F F \_$Marketing is a function of the capacity of the functional food system (FF_System_Capacity), Business_Opportunity and the rate of increase of system capacity. The logic is that FF_Marketing is at its peak when the product of business opportunity and system capacity increases are at their peak. $W o M_{A}$ is the word of mouth effect on awareness modelled with the standard formulation of word of mouth effect (Sterman, 2000). EoC is the implementation of the Effect_of_Crises. The change in Tw is given by: 


$$
\mathrm{T}_{\mathrm{W}}=\left(\mathrm{FF} \text { marketing }+\mathrm{WoM}_{\mathrm{W}}\right) \mathrm{x}(1+\mathrm{EoC})
$$

where $W o M_{W}$ is implemented in a similar manner to $W o M_{A}$. GI is not present in this equation because so far government initiatives have succeeded only in raising population awareness about nutrition issues. Evidence for this, are the rising levels of obesity in most developed countries (Mermel, 2004). The change in diet $\left(T_{D}\right)$ is given below:

$$
\mathrm{T}_{\mathrm{D}}=\left(\mathrm{PT} \times \mathrm{WoM}_{\mathrm{D}}+\mathrm{FF} \text { marketing }\right) \text { x Capacity Sufficiency }
$$

Again, $W o M_{D}$ is implemented as $W o M_{W}$ and $W o M_{A}$. FF_marketing is obviously an influence. $P T$ (Public_Trust_in_novel_foods) is a variable that decreases as a result of food crises limiting the shift towards the adoption of processed foods, and is reinstated with the increase in regulation and scientific research. Capacity_Sufficiency is also limiting the inflow of users to the stock $\mathrm{S}_{4}$. The logic behind this is that when there is little product visibility or supply in the market, it results in lower market uptake (Rogers, 2003).

The magnitude of Business_Opportunity (BO) (equation 4) increases with Capacity_Requirement for functional foods and the intensity of the Need_to_reduce_drug_R_\&_D costs relative to a reference level. It also depends on the existing FF_system_capacity, on the occurrence of Food_Crises and of course on the ratio of the population that has made the transition from being unaware, to any of the subsequent states $\mathrm{S}_{2}-\mathrm{S}_{4}$. Capacity_Requirement is a weighted average of $\mathrm{S}_{2}-\mathrm{S}_{4}$ user stocks and represents industry expectations about required capacity for functional foods. It is assumed that the flow of required resources and capabilities is proportionate to the magnitude of Business_Opportunity and it is aggregated in rate of FF_system_capacity_increase. RWP (Ratio of Willing Population) is the ratio $\left(\mathrm{S}_{2}+\mathrm{S}_{3}+\mathrm{S}_{4}\right) /$ Total population of consumers.

$\mathrm{BO}=($ Capacity Requirement $\mathrm{x}$ Need to reduce drug R\&D cost / Nominal Need to Reduce Drug R\&D Cost $) \times(1+$ EoC) $x$ RWP / FF system capacity

\subsection{Reproduction of the Emergence of Functional Foods - Simulation Experiments}

The model is used as a means to illustrate in principle the proposed methodology. There is certainly some uncertainty over values particular variables take. However, as the main purpose of the paper is to just discover and justify event-producing mechanisms (causal relations), stochastic approaches to modeling or Monte Carlo simulation are not necessary. These approaches are more suitable for policy 
making and analysis purposes. Consequently, the number of simulations run aims to explore the generative hypothesis and assess the effect of the mechanisms it includes. This was done by varying: (i) the timing of the food crises (Figure 3), (ii) the rate of scientific advances (Figure 4), (iii) industry expectations on functional food market penetration (Figure 5), (iv) regulation on food products (Figure 6). The variable observed was the functional foods market share that indicates their degree of diffusion and the extent of the corresponding niche. The simulation horizon in all the runs was from 1980 to 2040.

In order to test the timing of interactions among two systems, the start of the crises was shifted from its reference year 1995 to 1985 . This drives people earlier in states $S_{2}, S_{3}$, where they were aware and willing to make dietary changes. Consequently, the functional foods diffusion began earlier than in the reference scenario that corresponds to the behaviour observed in reality. However, as scientific advances, regulation and pressures on the two parent systems are not that intense, the business opportunity is small. Since scientific results and regulation are at an early stage, public trust in functional foods does not recover swiftly after the crisis, thus resulting in lower market penetration. Shifting the crisis forward in time to 2005 resulted in a higher market penetration. At that time there are more scientific results and regulation in place, the diffusion of functional foods had already begun and the crisis reinforces it. The effect of crisis is also illustrated in a simulation run with no crisis. This leaves public trust intact but the awareness transition $T_{A}$ is considerably delayed, delaying market diffusion.

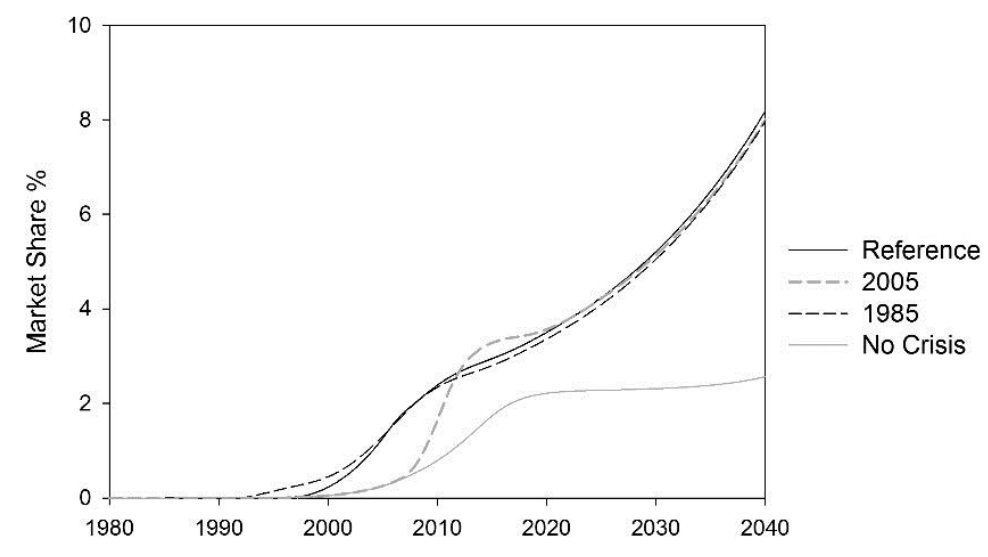

Figure 3. The timing of the food crises

The role of scientific progress and its timing was also examined (Figure 4). Obviously, no scientific advances resulted in no functional food development and zero market shares, while high rates of scientific progress resulted in corresponding higher functional food market shares. This is because early knowledge accumulation and subsequent diffusion, leads to early population shift. 


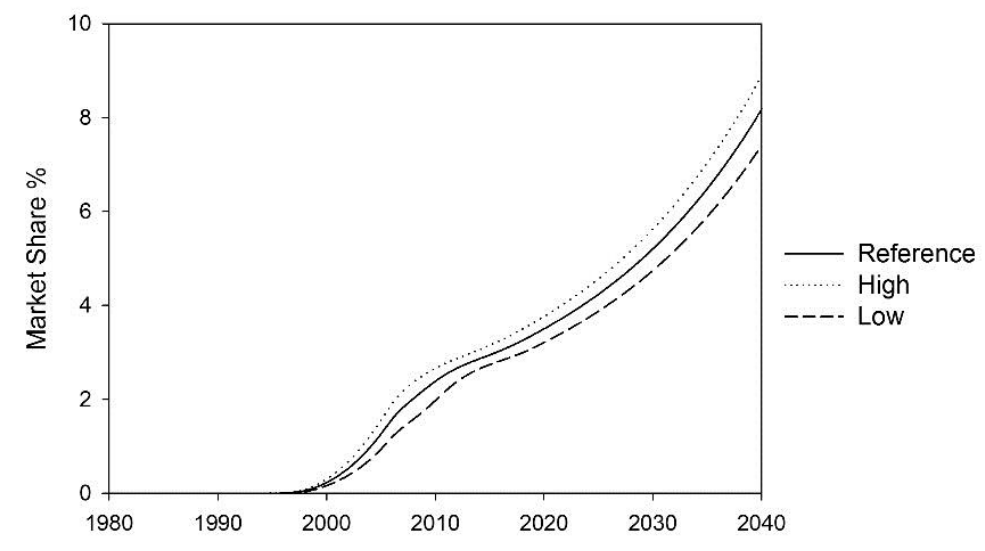

Figure 4. The role of scientific advances

Figure 5 shows the effect of different industry expectations that drive Capacity_Requirement on functional food market share. This variable has a significant impact on market share, provided that landscape pressures persist. Industry expectations are assumed to drive the investment and resources flows from the two 'parent' regimes and thus the eventual development of the functional food system. In all three scenarios, the stock of adopters of functional foods $\mathrm{S}_{4}$ is given the higher weight while the weights of stocks $S_{2} S_{3}$ are varied, with $S_{2}<S_{3}$ in every case.

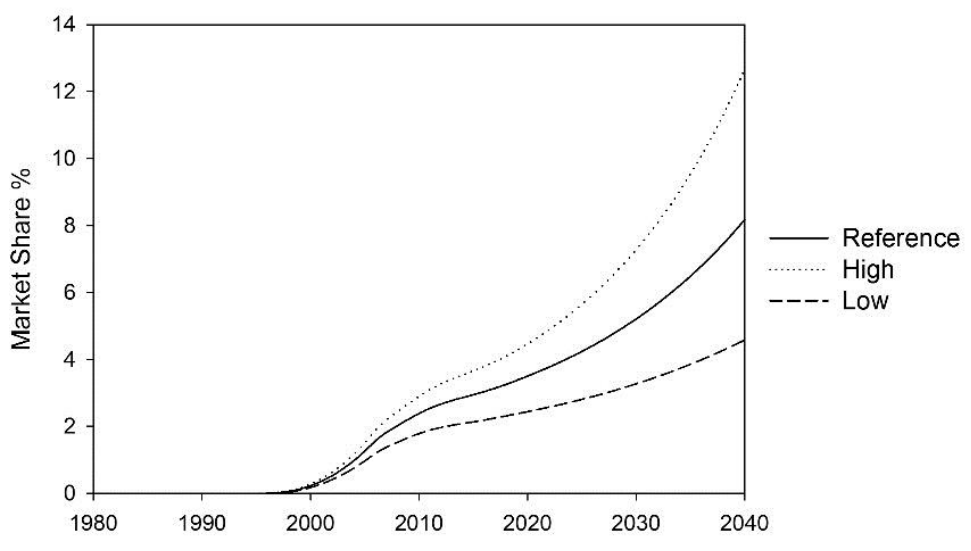

Figure 5. Industry expectations on functional food market penetration

Testing for the effects of different pace of government health initiatives (GI) did not result in significant changes in functional food uptake, as it was assumed to have a small effect on changing dietary habits (Mermel, 2004). On the contrary, regulation did have a significant effect on functional food diffusion, especially long term (Figure 6). This corresponded to the fact that the lack of a widely accepted functional food definition and a uniformly regulated environment slowed down functional food market penetration (Doyon and Labrecue, 2008). 


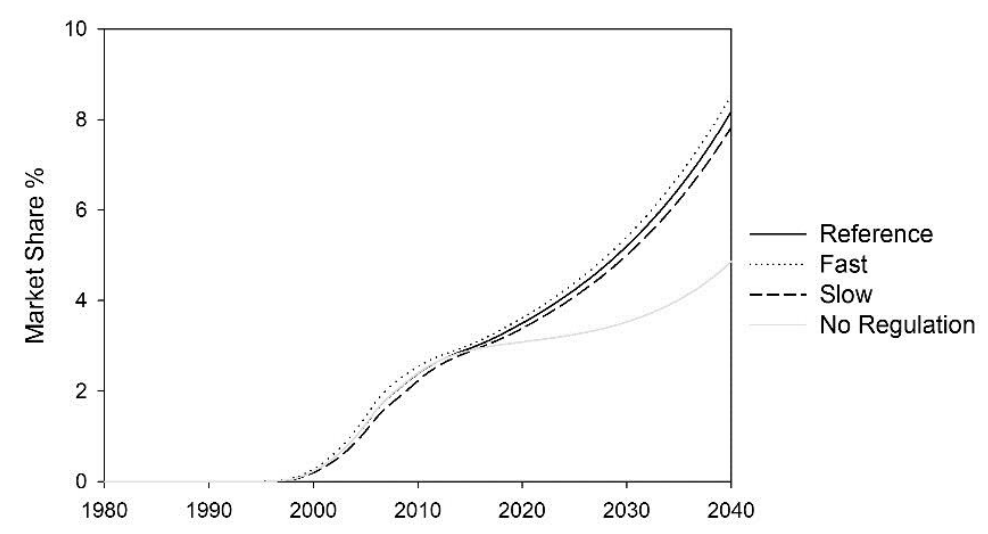

Figure 6 The effect of regulation in food products

Further tests were carried out. For example, removing the pressure of pharmaceutical R\&D costs. This resulted in weaker diffusion patterns than the reference run, since there were no pressures to which the pharmaceutical firms ought to respond. Removing the health care cost pressure resulted in no transition in the awareness of consumers blocking the business opportunity for pharmaceuticals.

Overall, simulation results exhibited a consistent $S$ and saddle pattern (Peres et al., 2010) with some variability, which was expected. This indicates that the long-term behaviour observed corresponds to the underlying feedback structure (Figure 2). The reference run resulted in a $2.5 \%$ market share in 2010 which corresponds to an estimated $2 \%$ global average with $90 \%$ of sales in Europe, US and Japan with European market share being below 1\% and US above 3\% (Siro et al., 2008). In conclusion, drawing on the behaviour patterns observed, it is possible to claim that the model includes the necessary and adequate causes for producing the behaviour detailed in the case and expressed in the main hypothesis (Figure 2).

\section{Conclusions}

This paper proposed a retroductive systems methodology for socio-technical systems transitions research that uses system dynamics modelling in connection with the qualitative case study method to enhance understanding by introducing quantitative information. The methodology was applied in a multi (socio-technical) system interaction case. There were two complementary motivations for this research drawing in part from criticisms to the MLP on socio-technical transitions. The first was to propose an alternative research methodology for socio-technical systems transition research suitable for handling the epistemological complexity of multi system interaction cases.

Adopting a systems perspective focusing on the interactions among the drivers of change, and critical realism as the underpinning philosophy of science, we proposed retroduction as the inference mode 
for the identification of the causes that create specific transitions. Retroduction was employed for considering and evaluating many possible explanations based on the partial subjective understanding of the micro-structures of reality considered as responsible for the macro-events (transitions) observed. We argued that after consolidating these partial understandings in a plausible narrative it was necessary to adopt a systems perspective for capturing the dynamic nature of the micro-structures (underlying mechanisms) the narrative implies, and for evaluating through computer simulation their validity as generators of the transition observed.

The second motivation for the paper was to investigate a multi-system transition case since there are only a few cases have been published so far (Geels, 2007b; Raven, 2007a; Raven and Verbong, 2007) and none involves simulation modelling. The case and model presented in the paper are fundamentally multi system. System interactions and the mutual contribution of capabilities from the pharmaceuticals and the food systems, which fulfil distinct, non-interchangeable social needs, led to the development of the functional foods niche. The food system fulfils the need of human nutrition, the pharmaceuticals that of medicine discovery and supply, and the functional foods the emerging need for proactive/health enhancing and curing nutrition. That is, this leads to a transition pathway which is not included in the existing MLP transition typology: two systems (or more) interact under the landscape and internal pressures they face, they continue to coexist (nutrition/food and pharmaceuticals-based health maintenance) while a third one emerges (functional foods), without them decaying or disappearing.

The case of functional foods differs from previous multi system cases because the food and pharmaceutical systems fulfil functions that are not interchangeable as in the case of heat and power generation (Raven and Verbong, 2007) or the case of the emergence of rock'n'roll (Geels, 2007b). The functional foods case resembles the case of coevolution of the electricity and waste system coevolution in the Netherlands (Raven, 2007a). However, this does not result in the emergence of a new system or regime, as there is no new regulation about a new product or technology. Regulation rather drives the symbiotic relationship between the two existing regimes towards integration. Indeed, multi utility companies evolved and encompassed waste processing and energy related activities. In broad terms, the product stream of the waste regime was diverted to the electricity generation regime.

The paper makes a solid step towards the study of multi-system transitions by proposing a methodology and illustrating its use. The adoption of a holistic perspective and the integration of a modelling and simulation in a pluralistic methodology is a way to address the complexity of multi system transition processes. Case study development along with a retroductive employment of 
modelling and simulation can contribute to the shift from researching single system/technology transitions to multi system/technology transitions. Such a methodology increases confidence in the factors and ways that drive multi system transitions. Hence, the paper is a step towards coping methodologically with sustainability transitions that often concern multi system interactions, and as such, is important for the future agenda of transition studies. Since transition research is a relatively new area, it is hoped that this paper will contribute to development of better theory and a more consistent, rigorous and hence powerful methodological directions in transition studies. Future research could look into the conditions under which multi regime interactions lead to emergence of convergence between systems as documented in the literature already.

\section{Acknowledgements}

The authors would like to thank Scott Cunningham for commenting on previous versions of the paper.

\section{References}

Adamides, E., Papachristos, G., Pomonis, N., 2012. Critical realism in supply chain research: Understanding the dynamics of a seasonal goods supply chain. International Journal of Physical Distribution \& Logistics Management 42(10), 906-930.

Allarakhia, M., Walsh, S.T., 2011. Managing knowledge assets under conditions of radical change: The case of the pharmaceutical industry. Technovation 31(2-3), 105-117.

Archer, M., Bhaskar, R., Collier, C., Lawson, T., Norrie, A., 1998. Critical Realism: Essential Readings, Routledge, London, UK.

Ashton, J., Seymour, H., 1990. The New Public Health. Open University Press, Milton Keynes.

Bagchi, D., 2008. Nutraceutical and functional food regulations in the United States and around the world. Academic Press.

Bech-Larsen, T., Scholderer, J., 2007. Functional foods in Europe: Consumer research, market experiences and regulatory aspects, Trends Food Science and Technology 18, 231-234.

Bergek, A., Jacobsson, S., Carlsson, B., Lindmark, S., Rickne, A., 2008. Analyzing the functional dynamics of technological innovation systems: A scheme of analysis. Research Policy 37, 407-429.

Bergman, N., Haxeltine, A., Whitmarsh, L., Kohler, J., Schilperoord, M., Rotmans, J., 2008. Modelling socio technical transition patterns and pathways, Journal of Artificial Societies and Social Simulation, 11(3)

Best, D., 1996. A functional pharmacopoeia. Prepared Foods 165(4), 38-44.

Bhaskar, R., 2008. A Realist Theory of Science, Verso, London, UK.

Boucher, P., 2012. Things, names, judgments and the LRS lens: a critical realist analysis of the biofuel controversy in the UK. Science Communication doi:10.1177/1075547012454596

Buthe, T., 2002. Taking temporality seriously: Modeling history and the use of narratives as evidence. American Political Science Review 96(3), 481-493.

Cardello, A., Schutz H.G., Lesber, L.L. 2007. Consumer Perceptions of foods processed by innovative and emerging technologies: A conjoint analytic study. Innovative Food Science and Emerging Technologies 8, 73-83.

Carlsson, B., Jacobsson, S., Holmen, M., Rickne, A., 2002. Innovation systems: analytical and methodological issues. Research Policy 31, 233-245.

Carlsson, B., Stankiewicz, R., 1991. On the nature, function and composition of technological systems. Journal of Evolutionary Economics 1(2), 93-118.

Checkland, P., Scholes, J., 1999. Soft systems methodology in action. Wiley, London.

Cockburn, M.I., Henderson, M.R., 2001. Scale and scope in drug development: unpacking the advantages of size in pharmaceutical research. Journal of Health Economics 20, 1033- 1057.

Coenen, L., Diaz Lopez, F.J., 2010. Comparing systems approaches to innovation and technological change for sustainable and competitive economies: an explorative study into conceptual commonalities, differences and complementarities. Journal of Cleaner Production 18, 1149-1160.

Coppens, P., Da Silva, F.M., Pettman, S., 2006. European regulations on nutraceuticals, dietary supplements and functional foods: a framework based on safety. Toxicology 221, 59-74.

Coveney, J., 2003. Why food policy is critical to public health, Critical Public Health 13(2), 99-105. 
Cronin, M., Gonzalez, C., Sterman, J.D., 2009. Why don't well-educated adults understand accumulation? A challenge to researchers, educators, and citizens, Organizational Behavior Human Decision Process 108(1), 116-130.

Curran, C-S., Broring, S., Leker, J., 2010. Anticipating converging industries using publicly available data. Technology Forecasting and Social Change 77(3), 385-395.

Danermark, B., Ekstrom, M., Jakobsen, L, Karlsson, J., Bhaskar, R., 2002. Explaining society: An introduction to critical realism in the social sciences. Routledge, London.

Davis, P.J., Eisenhardt, M.K., Bingham, B.C., 2007. Developing theory through simulation methods, Academy of Management Review 32(2), 480-499.

Denton, T.F., Gafni, A., Spencer, G.B., 2002. Exploring the effects of population change on the costs of physician services. Journal of Health Economics 21, 781-803.

Diehl, E., Sterman, J.D., 1995. Effects of feedback complexity on dynamic decision making. Organizational Behavior Human Decision Process 62(2), 198-215.

DiMaggio, P.J., 1995. Comments on "What theory is not". Administrative Science Quarterly 40(3), 391-397.

DiMaggio, P.J., Powell, W.W., 1983. The iron cage revisited: institutional isomorphism and collective rationality in organizational fields. American Sociological Review 48, 147-160.

DiMasi, J.A., 2001. New drug development in U.S. 1963-1999. Clinical Pharmacology and Therapeutics 69, $286-296$.

DiMasi, J.A., Hansen, R.W., Grabowski, H.G., 2003. The price of innovation: new estimates of drug development costs. Journal of Health Economics 22, 151-185.

DiMasi, J.A., Hansen, R.W., Grabowski, H.G., Lasagna, L., 1991. Cost of Innovation in the Pharmaceutical Industry. Journal of Health Economics 10, 107-142.

DiMasi, J.A., Paquette, C., 2004. The economics of follow on drug research and development: trends in entry rates and the timing of development. PharmacoEconomics 2, 1-14.

Doyon, M., Labrecque, J., 2008. Functional foods: a conceptual definition. British Food Journal 110(11), $1133-1149$.

Eden, S., 2011. Food labels as boundary objects: How consumers make sense of organic and functional foods. Public Understanding of Science 20(2), 179-194.

Edquist, C., 1997. Systems of innovation approaches - Their emergence and their characteristics, In: Edquist, C. (Eds.) Systems of Innovation: Technologies, Institutions and Organizations, Pinter, London, pp. 1-35

EFPIA, 2014. The pharmaceutical industry in figures 2014 edition, report of European Federation of Pharmaceutical Industries and Associations, online access (http://www.efpia.eu/uploads/Figures_2014_Final.pdf 17/2/2015)

Eisenhardt, K.M., Graebner, M.E, 2007. Theory building from cases: Opportunities and challenges. Academy of Management Journal 50(1), 25-32.

Fischer, H.R., 2001. Abductive reasoning as a way of worldmaking, Foundations of Science 6, 361-383.

Fleetwood, S., 2005. Ontology in organization and management studies: a critical realist perspective. Organization 12(2), 197-222.

Forrester, J.W., 1961. Industrial Dynamics, Pegasus Communications.

Forrester, J.W., 1969. Urban Dynamics, Pegasus Communications.

Freeman, C., 1987. Technology policy and economic performance: lessons from Japan. London, Pinter Publishers.

Frewer, L.J., Miles, S., Marsh, R., 2002. The media and genetically modified foods: Evidence in support of social amplification of risk. Risk Analysis 22, 701-711.

Gao, P., 2015. Government in the catching-up of technology innovation: Case of administrative intervention in China. Technology Forecasting and Social Change 96, 4-14.

Garud, R., Karnoe, P., 2001. Path dependence and creation. Lawrence Erlbaum Associates, London, UK

Geels, F.W., 2004. From sectoral systems of innovation to socio technical systems: insights about dynamics and change from sociology and institutional theory. Research Policy 33, 897-920.

Geels, F.W., 2005. Processes and patterns in transitions and system innovations: refining the co-evolutionary multilevel perspective. Technological Forecasting and Social Change 72, 681-696.

Geels, F.W., 2007a. Feelings of discontent and the promise of middle range theory for STS: Examples from technology dynamics. Science Technology Human Values 32(6), 627-651.

Geels, F.W., 2007b. Analysing the breakthrough of rock 'n' roll (1930-1970) multi regime interaction and reconfiguration in the multi level perspective. Technological Forecasting and Social Change 74, 1411-1431.

Geels, F.W., 2010. Ontologies, sociotechnical transitions (to sustainability) and the multi level perspective. Research Policy 39(4), 495-510.

Geels, F.W., Schot, J., 2007. Typology of sociotechnical transition pathways. Research Policy 36, 399-417.

Geels, F.W., 2011. The multi-level perspective on sustainability transitions: responses to seven criticisms. Environmental Innovation and Societal Transition 1, 24-40.

Genus, A., Coles, A.M., 2008. Rethinking the multi level perspective of technological transitions. Research Policy 37 , 1436-1445.

Grabowski, G.H., Kyle, M., 2007. Generic competition and market exclusivity periods in pharmaceuticals. Management Decision Economics 28, 491-502.

Harrison, J.R., Zhiang, L., Carroll, G.R., Carley, K.M., 2007. Simulation modelling in organizational and management research. Academy of Management Review 32(4), 1229-1245.

Hearle, K., Koenig, L., Rudowitz, R., Siegel, J.M., Dobson, A., Ho, S., 2003. Drivers of expenditure growth in outpatient care services. American Journal Management Care 9, SP25-SP33. 
Hekkert, M.P., Suurs, R.A.A., Negro, S.O., Kuhlmann, S., Smits, R.E.H.M., 2007. Functions of Innovation Systems: A new approach for analysing technological change. Technology Forecasting Societal Change 74, 413-432.

Holtz, G., 2011. Modelling transitions: An appraisal of experiences and suggestions for research. Environmental Innovation and Societal Transitions 1, 167-186.

Hommels, A., Peters, P., Bijker, E.W., 2007. Techno therapy or nurtured niches? Technology studies and the evaluation of radical innovations. Research Policy 36, 1088-1099.

Jacobzone, S., 2000. Pharmaceutical Policies in OECD Countries: Reconciling Social and Industrial Goals. OECD Labour Market and Social Policy Occasional Papers, No. 40, OECD Publishing.

Jensen, J.E., 1987. Research expenditures and the discovery of new drugs. Journal of Industrial Economics 36(1), 8395.

Kallinikos, J., Hasselbladh, H., Marton, A., 2013. Governing social practice: Technology and institutional change. Theory and Society 42, 395-421.

Kohler, J., Whitmarsh, L., Nykvist, B., Schilperoord, M., Bergman, N., Haxeltine, A., 2009. A transitions model for sustainable mobility, Ecological Economics 68, 2985-2995.

Konrad, K., Truffer, B., Voss, J., 2008. Multi-regime dynamics in the analysis of sectoral transformation potentials: evidence from German utility sectors. Journal of Cleaner Production 16, 1190-1202.

Kopainsky, B., Luna-Reyes, L.F., 2008. Closing the loop: Promoting synergies with other theory building approaches to improve system dynamics practice. Systems Research and Behavioral Science 25, 471-486.

Langley, A., 1999. Strategies for theorizing from process data. Academy of Management Review 24(4), 691-710.

Lauridsen, E.H., Jorgensen, U., 2010. Sustainable transition of electronic products through waste policy. Research Policy 39, 486-494.

Lorgeril, M., Salen, P., Martin, J.L., Monjaud, I., Boucher, P., Mamelle, N., 1998. Mediterranean dietary pattern in a randomized trial: prolonged survival and possible reduced cancer rate. Archives of Internal Medicine 158, 11811187.

Lundvall, B.A., 1992. National Systems of Innovation. Towards a Theory of Innovation and Interactive Learning. London and New York. Pinter Publishers.

Lundvall, B.A., 2010. National systems of innovation: Toward a theory of innovation and interactive learning. Anthem Press, UK

Mancarella, P., 2014. MES (multi-energy systems): An overview of concepts and evaluation models. Energy 65, 1-17.

Manicas, P.T., 2006. A Realist Philosophy of Social Science: Explanation and Understanding, Cambridge University Press, Cambridge, UK.

Mark-Herbert, C., 2004. Innovation of a new product category - Functional Foods. Technovation. 24, 713-719.

Meadows, D.H., Meadows, D.L., Randers, J., Behrens, W.W., 1972. The limits to growth. Universe Books, New York.

Mermel, L.V., 2004. Old paths new directions: the use of functional foods in the treatment of obesity. Trends Food Science Technology 15, 532-540.

Miettinen, T., Puska, P., Gylling, H., Vanhanen, H., Vartiainen, E., 1995. Reduction of serum cholesterol with sitostanol-ester margarine in a mildly hypercholesterolemic population. New England Journal of Medicine 333(2), 1308-1312.

Mingers, J., 2000. The contribution of critical realism as an underpinning philosophy for OR/MS and systems, Journal of Operations Research Society 51, 1256-1270.

Mingers, J., 2004. Real-izing information systems: critical realism as an underpinning philosophy for information systems. Information and Organization 14(2), 87-103.

Mowery, D.C., 1998. The changing structure of the US national innovation system: implications for international conflict and cooperation in R\&D policy. Research Policy 27(6), 639-654.

Muller, R.F., Reinhold, T., Berghofer, A., Willich, N.S., 2008. Health economic burden of obesity in Europe, European Journal of Epidemiology 23, 499-509.

Nelson, R.R., 1993. National Innovation Systems: A Comparative Analysis. New York and Oxford: Oxford University Press.

Newhouse, J.P., 1992. Medical Care Costs: How Much Welfare Loss?. Journal of Economic Perspectives 6(3), 3-21.

Niva, M., 2007. All foods affect health: Understandings of functional foods and healthy eating among health oriented Finns. Appetite 48, 384-393.

OECD, 2006. Projecting OECD Health and Long-term Care Expenditures: What are the Main Drivers?, OECD Economics Department Working Paper No. 477

Okunade, A.A., Murthy, V.N.R., 2002. Technology as a 'major driver' of health care costs: A cointegration analysis of the Newhouse conjecture. Journal of Health Economics 21, 147-159.

Papachristos G., 2011. A system dynamics model of socio-technical regime transitions. Environmental Innovation and Societal Transitions 1(2), 202-233.

Papachristos, G., Sofianos, A., Adamides, E., 2013. System interactions in socio-technical transitions: extending the Multi-Level Perspective. Environmental Innovation and Societal Transition 7, 53-69.

Papachristos G., 2014. Towards multi-system sociotechnical transitions: why simulate. Technology Analysis and Strategic Management 26(9), 1037-1055.

Peirce, C.S., 1958. Collected Papers of Charles Sanders Peirce. (eds.) C. Hartshorne, P., Weiss, A.W., Burks. Cambridge, Massachusetts. 
Peres, R., Muller, E., Mahajan, V,. 2010. Innovation diffusion and new product growth models: A critical review and research directions. International Journal of Research in Marketing 27, 91-106.

Pettigrew, A.M., 1992. The character and significance of strategy process research. Strategic Management Journal 13, $5-16$.

Potter, J.D., Steinmetz, K., 1996. Vegetables, fruit and phytoestrogens as preventive agents, IARC Scientific Publications 139, 61-90.

Raven, R., Verbong, G., 2007. Multi regime interactions in the Dutch energy sector: The case of combined heat and power technologies in the Netherlands 1970-2000. Technology Analysis \& Strategic Management 19(4), $491-507$.

Raven, R., 2007a. Co-evolution of Waste and Electricity Regimes: multi-regime dynamics in the Netherlands (1969 2003). Energy Policy 35(4), 2197-2208.

Raven, R., 2007b. Niche accumulation and hybridisation strategies in transition processes towards a sustainably energy system: An assessment of differences and pitfalls. Energy Policy 35, 2390-2400.

Reed, M.I. (2009), Critical realism in critical management studies. In: Alvesson, M., Bridgman, T. and Willmott, H. (Eds.), The Oxford Handbook of Critical Management Studies, Oxford University Press, Oxford, pp. 52-75.

Richardson, G.P., 2011. Reflections on the foundations of system dynamics. System Dynamics Review 27(3), $219-243$.

Rogers, E., 2003. The diffusion of innovations, 5th edition, Free Press.

Rohr, A., Luddecke, K., Drusch, S., Muller, J.M., Alvensleben, V.R., 2005. Food quality and safety consumer perception and public health concern. Food Control 16, 649-655.

Safarzynska, K., van den Bergh, J., 2010. Demand-supply coevolution with multiple increasing returns: policy analysis for unlocking and systems transitions. Technology Forecasting Social Change 77(2), 297-317.

Safarzynnka, K., Frenken, K., van den Bergh, J.C.J.M., 2012. Evolutionary theorizing and modeling of sustainability transitions. Research Policy 41, 1011-1024.

Samara, E., Georgiadis, P., Bakouros, I., 2012. The impact of innovation policies on the performance of national innovation systems: A system dynamics analysis. Technovation 32, 624-638.

Sayer, A. (2004), Foreword: why critical realism?. In: Fleetwood, S. and Ackroyd, S. (Eds.), Critical Realist Applications in Organisation and Management Studies, Routledge, London, pp. 6-20.

Scherer, F.M., 2001. The link between gross profitability and pharmaceutical R\&D spending. Health Affairs 20(5), 216220.

Schilperoord, M., Rotmans J., Bergman N. 2008. Modelling societal transitions with agent transformation. Computational and Mathematical Organization Theory 14 (4), 283-301.

Schwaninger, M., Grosser, S., 2008. System dynamics as model-based theory building. Systems Research and Behavioral Science 25, 447-465.

Shove, E., Walker, G., 2007. CAUTION! Transitions ahead: politics, practice, and sustainable transition management. Environment Plan A 39, 763-770.

Silventoinen, K., Sans, S., Tolonen, H., Monterde, D., Kuulasmaa, K., Kesteloot, H., Tuomilehto, J., 2004. Trends in obesity and energy supply in the WHO MONICA project. International Journal of Obesity 28, 710-718.

Siro, I., Kapolna, E., Kapolna, B., Lugasi, A., 2008. Functional Foods. Product development, marketing and consumer acceptance - a review. Appetite 51, 456-467.

Smith, A., Voß, J-P., Grin, J., 2010. Innovation studies and sustainability transitions: The allure of the multi-level perspective and its challenges. Research Policy 39, 435-448.

Sterman, J.D., 1989a. Misperceptions of feedback in dynamic decision making. Organizational Behavior Human Decision Process 43(3), 301-335.

Sterman, J.D., 1989b. Modelling managerial behaviour: Misperceptions of feedback in a dynamic decision making experiment, Management Science 35(3), 321-339.

Sterman, J.D., Business Dynamics: Systems Thinking and Modelling for a Complex World. Irwin McGraw-Hill, New York.

Sterman, J.D., Sweeney, L.B., 2007. Understanding public complacency about climate change: adults' mental models of climate change violate conservation of matter. Climatic Change 80(3-4), 213-238.

Sutton, R.I., Staw, B.M., 1995. What theory is not. Administrative Science Quarterly 40, 371-384.

Tierney, R., Hermina, W., Walsh, S. 2013. The pharmaceutical technology landscape: A new form of technology roadmapping. Technological Forecasting \& Social Change 80, 194-211.

Titchener, G.D., Sapp, S.G., 2002. A comparison of two approaches to understanding consumer opinions of biotechnology. Journal of Social Behavior and Personality 30(4), 373-382.

Unruh, G.C., 2000. Understanding carbon lock in, Energy Policy 28, 817-830.

Upham, P., Carney, S., Klapper, R., 2014. Scaffolding, software and scenarios: Applying Bruner's learning theory to energy scenario development with the public. Technological Forecasting \& Social Change 81, 131-142.

Van de Ven, A.H., 1992. Suggestions for studying strategy process: A research note. Strategic Management Journal 13, 169-188.

Verbeke, W., 2005. Consumer acceptance of functional foods: sociodemographic, cognitive and attitudinal determinants. Food Quality and Preference 16(1), 45-57.

Verbeke, W., Ward, R., 2001. A fresh meat almost ideal demand system incorporating negative TV press and advertising impact, Agricultural Economics 25, 359-374.

Weick, K.E., 1989. Theory construction as disciplined imagination. Academy of Management Review 14(4), 516-531. 
Whetten, D.A., 1989. What constitutes a theoretical contribution. Academy of Management Review 14(4), 490-495.

Wuisman, J.J.J.M., 2005. The logic of scientific discovery in critical realist social scientific research. Journal of Critical Realism 4(2), 366-394.

Yin, R.K., 2003. Case study research: Design and methods. 3rd edition, Sage Publications, CA, US. 